\title{
LETTER TO THE EDITOR (JANuARY 1, 2019) CONCERNING THE PAPER "IMPACT OF AIR POLLUTION ON DEPRESSION AND SUICIDE"
}

Dear Editor,

Gładka et al. [1], in their careful review of the literature, gave indications of how air pollution can influence the suicide rate. We must remember, however, that air pollution and global warming are both consequences of climate change and are deeply associated [2].

There is strong evidence that high ambient temperature is associated with the suicide risk, and increased morbidity and mortality among people with known mental health problems [3]. Many studies have highlighted the close relationships existing between heat waves and mental disorders, such as psychological exhaustion, anxiety, mood disorders, and dementia, as well as the association of extreme heat exposures with aggressive behaviors [4].

Our understanding of the combined effects of heat and air pollution on mental health and suicide is still limited [5]. Among other things, the increase in temperature accelerates metabolism, and this could increase the toxic effect of environmental pollutants. At present, we cannot say whether the association between the 2 factors is additive or multiplicative.

Ultimately, we agree with Gładka et al. [1] that further research is needed to explore depression morbidity and suicide statistics. The comparison of geographical areas with high average concentrations of pollutants to those with low pollutants may be useful, but research should not neglect the confounding role played by heat waves.
An epidemiological approach based on large population surveys, and the increasing availability of environmental and public health databases across the world [6], could be useful in gaining a better understanding of these complex relationships.

Key words:

air pollution, climate change, epidemiology, global warming, mental health, suicide

\section{REFERENCES}

1. Gładka A, Rymaszewska J, Zatoński T. Impact of air pollution on depression and suicide. Int J Occup Med Environ Health. 2018;31(6):711-21, https://doi.org/10.13075/ijomeh. 1896.01277.

2. Chirico F. Comments on "Climate change and public health: a small frame obscures the picture". New Solut. 2018;28(1):57, https://doi.org/10.1177/1048291117752463.

3. Thompson R, Hornigold R, Page L, Waite T. Associations between high ambient temperatures and heat waves with mental health outcomes: a systematic review. Public Health. 2018;161:171-91, https://doi.org/10.1016/j.puhe.2018.06.008.

4. Padhy SK, Sarkar S, Panigrahi M, Paul S. Mental health effects of climate change. Indian J Occup Environ Med. 2015;19(1):3-7, https://doi.org/10.4103/0019-5278.156997.

5. Center for International Climate Research (CICERO) [Internet]. Reed EU. Double trouble: Climate change and air 
pollution; 2018 Apr 17 [cited 2018 Dec 30]. Available from: https://www.cicero.oslo.no/en/posts/climate-news/doubletrouble-climate-change-and-air-pollution.

6. Chirico F, Magnavita N. The significant role of health surveillance in the occupational heat stress assessment. Int J Biometerol. 2019;63(2): 193-4, https://doi.org/10.1007/s00484-018 $-1651-\mathrm{y}$.

\author{
Francesco Chirico ${ }^{1,2}$ and Nicola Magnavita ${ }^{2}$ \\ ${ }^{1}$ Ministry of Interior, Rome, Italy \\ Health Service Department, State Police \\ ${ }^{2}$ Catholic University of the Sacred Heart, Rome, Italy \\ Department of Woman/Child and Public Health
}

Corresponding author: Francesco Chirico

Ministry of Interior

Health Service Department, State Police

Via Umberto Cagni, 21

20162 Milano, Italy

(e-mail: medlavchirico@gmail.com)

This work is available in Open Access model and licensed under a Creative Commons Attribution-NonCommercial 3.0 Poland License - http://creativecommons.org/ licenses/by-nc/3.0/pl/deed.en. 